\author{
Alberto Espezel \\ Facultad de Teología \\ Universidad Católica de Argentina \\ Seminario San Miguel
}

\title{
La cristología dramática de Balthasar
}

Intentamos simplemente recorrer en forma breve varios temas de la cristología balthasariana. Seguimos el camino siguiente:
a) La mirada desde arriba
b) Cristología de arriba
c) Riesgo de neocalcedonismo
d) La Cruz y la Stellvertretung
e) El descenso, crítica y resultado
f) La superación de la neoescolástica
g) La influencia de Adrienne

\section{a. LA MIRADA DESDE ARRIBA}

En la teología balthasariana vemos una lectura trinitaria de todos los temas teológicos. De modo que en todas las áreas de su teología se advierte una dimensión trinitaria fundante. Dicho con otras palabras, la teología balthasariana tiene una profundidad trinitaria, hable del tema que hable. Esto ocurre a fortiori en su cristología. La figura cristológica con su fundamento trinitario tiñe a su vez su teología entera. No pocos teólogos contemporáneos han reflexionado también desde esta mirada trinitaria: Greshake, Hoffman, Schwager, Coda y otros. De algún modo esto ya presupone lo que llamamos una mirada desde arriba.

Para entrar en su cristología tratemos de contemplar el sentido de la Teodramática. Como lo recuerda Mons. Henrici, para el autor, su obra, más que una trilogía es un tríptico, es decir, una obra de arte tripartita, cuya parte principal se encuentra en el centro (la Teodramática), acompañada armónicamente por dos alas de la derecha y de la izquierda, que interpretan y orquestan el sentido de lo tratado en el panel del medio. Por eso, en el tríptico de Balthasar, la obra central es la Teodramática, y es allí donde pueden encontrarse huellas de los tratados teológicos tradicionales, elementos de una antropología teológica, de una cristología, de una mariología, de una soteriología, de una eclesiología, de una escatología y de una doctrina trinitaria (lo que no obsta a encontrar también elementos de estos tratados en la Estética y la Lógica teológica). 
La Teodramática constituye el intento de comprender la relación entre Dios y la humanidad en términos de una acción divina, o mejor, divino-humana. El Dios cristiano es un Dios que actúa en el mundo y la historia. No sólo un Dios que interviene (como los dioses en la mitología griega), sino que se empeña personalmente, primero para la salvación del pueblo elegido, luego para la salvación de toda la humanidad, dejando morir en la Cruz a su Hijo encarnado. Por ello los dioses de la tragedia griega se encontraban más cercanos al cristianismo que los dioses filosóficos de Platón o Aristóteles. "El diálogo decisivo entre la Antigüedad y el cristianismo no debía ser aquel desarrollado por milenios entre Platón y la teología patrístico-escolástica, cuanto más bien entre los trágicos griegos y los santos cristianos a propósito del sentido de la existencia humana" (Balthasar, Mi obra y epílogo, 1994, Milano, 64)

Respecto a la Teodramática, es importante tener en cuenta que la transposición del teatro a la historia de la salvación es análoga. La historia de los hombres no responde a un texto fijado definitiva o claramente por Dios de una vez para siempre. Se trata más bien del trazado de un marco o espacio donde se ha de representar y desarrollar la historia, con indicaciones generales. El texto es originariamente muy libre y llamado a ser ejecutado en un diálogo fecundo. Los roles no se encuentran totalmente definidos y precisados, sino que hay talentos y disposiciones a ser vividos por la libertad finita en diálogo con la libertad infinita. El mismo autor lo recuerda en un texto conocido de la Teología de la historia en relación con Jesús y el Espíritu que le apunta la voluntad paterna.: "(El Hijo bajo el Espíritu) ...se ha de comparar mucho más a un actor que al representar por primera vez un papel, lo recibe apuntado escena por escena y palabra por palabra. La encarnación no es la enésima representación de una tragedia que ya estaba hacía mucho tiempo preparada en el archivo de la eternidad. Es proceso originalísimo y tan nuevo como el nacimiento del Hijo desde el Padre, cumpliéndose ahora eternamente" (Teología de la Historia, Madrid, 1964, 47). El apuntador actúa en forma instantánea, acompaña cada hora, no anticipa nada, abre el juego a una acción totalmente original y novedosa.

Quizás podría traerse aquí a colación para desarrollar la intuición del autor, la idea teatral y musical de "improvisación", en la que el actor o ejecutante desarrolla su propia inventiva creadora en el interior del marco central puesto por el autor. La libertad del actor/ejecutante tiene un ancho margen creativo en diálogo con el autor, libre creador.

"No se renuncia jamás a la libertad de plasmar el rol que se está ejecutando; precristianamente ella es vista en una visual un poco angosta respecto a la visual cristiana y postcristiana, donde el rol (en el juego de la "improvisación") se hace todavía más plástico, pero la tensión originaria entre yo y el rol nunca es abandonada" TD I 234 "también el actor, como conformador o plasmador sucedáneo del personaje creado por el poeta, es un conformador libre, que a la par del autor debe concebir y disponer del personaje a representar en base a su visión unificante" (263). "El actor es escultor de sí mismo, al mismo tiempo director y orquesta, ...es un (artista) plástico que trabaja y configura en el propio material... la personalidad del actor es ser operario, técnico y artista" TD I 266.

No hay nadie, ninguna persona que se encuentra fuera del Teodrama como mero espectador, sino que todos se encuentran envueltos en él y habrán de dar cuenta en el último día por su participación en la obra. En nuestro tiempo, el debilitamiento del 
sentido de Dios, o su postergación en un deísmo larvado, lleva a una pérdida de percepción del sentido dramático de la historia.

El planteo teodramático, poniendo sobre el tapete la dimensión dramática de la historia de la salvación, es un hallazgo de Balthasar (hecho a continuación de su camino estético), seguido por no pocos teólogos contemporáneos. Este planteo ha facilitado la superación del callejón aparentemente sin salida entre la providencia y la libertad finita de cierta teología moderna, revalorizando una nueva mirada dialógica de alianza y de gracia entre Dios y el hombre. Queda así mostrada la redención como gracia ofrecida al hombre en forma sólo persuasiva.

La mirada antropológico-teológica balthasariana es la de un personalismo (análogo) dialogal filial en el encuentro de las dos libertades creadora y creada, donde el acento en la irreductibilidad del otro (con mayúsculas y con minúsculas, el Otro y el otro) muestra diferencias frente a toda una gama de formas de filosofía trascendental de origen más o menos kantiano, centradas más unilateralmente en el sujeto.

Dicho nuevamente, podríamos caracterizar la teología (y la filosofía) balthasarianas como fundadas en un personalismo metafísico objetivo, donde el acento personalista y dialogal -pensado también en forma trinitaria- no deriva en resultados antimetafísicos, sino que aspira a alcanzar una metafísica cristiana renovada, donde el amor aparezca como el trascendental absoluto (Holzer), y donde entonces el ser es considerado como don (relatio).

Acentuaríamos también el tema del personalismo filial, ya que allí yace uno de los centros de inspiración trinitaria de la antropología balthasariana, donde el modelo arquetípico cristológico de la existencia en recepción y en devolución eucarística aparece como fondo de su reflexión.

No se parte entonces de un sujeto trascendental que goza de una libertad incondicionada radical que se abre eventual o necesariamente al otro, sino que en Balthasar la filialidad invita desde su origen a una gozosa humildad receptiva mariana, bien consciente de la analogia entis y del lugar creatural del hombre y su participación en la filiación de Cristo.

En este sentido, la Teodramática podría ser leída como una respuesta original a la problemática moderna de la libertad del hombre, hecha desde la herencia patrística y escolástica, pero reformulada radicalmente, en su planteo dramático teatral, desde un personalismo con raíces trinitarias sin rasgos antimetafísicos. Parece central la formulación del diálogo de las libertades infinita y finita, y por ello los largos párrafos dedicados en la Teodramática a la oración como lugar de encuentro de las libertades, o dicho con palabras de Ratzinger, la oración considerada como laboratorio de libertad, todo lo cual presupone naturalmente, de algún modo, en forma previa, la percepción de la figura (la estética) que viene a liberar nuestra libertad cautiva. La relación entre ambas libertades es vista a menudo por Balthasar desde el misterio de la alianza y con categorías nupciales.

Recordemos la bellísima cita de Fénelon, hecha por nuestro autor:

"Nada había en mí que se encontrara antes de todos sus dones y que pudiera servir de recipiente para recibirlos. Su primer don, que puso en la base de todos los otros fue aquel que yo llamo mi yo; Dios me ha dado este yo; le soy deudor no sólo de todo lo que poseo, sino también de todo lo que soy. Oh don inaudito, 
dicho inmediatamente en nuestra lengua débil, pero que nuestro espíritu no llega jamás a comprender hasta el fondo. El Dios que me ha creado me ha dado a mí mismo como don; el yo que tanto amo no es sino un don de su bondad... sin éste yo no sería yo mismo, sin Dios no tendría ni el yo con el que poder amar, ni el amor con que poder amar este yo, ni la voluntad que lo ama, ni el pensamiento con el que me conozco. Todo es don; quien recibe estos dones es él mismo ante todo don recibido" (Lettres I, 4,1) TD II,1, 263.

Por otra parte, la distinción balthasariana establecida entre sujeto espiritual y persona para distinguir antropológicamente entre el momento creacional del hombre y el propiamente sobrenatural de la persona y misión teológicas, articuladas a su vez en el interior de la misión y persona de Cristo, nos parece teológicamente clara y valiosa. Sin embargo, a la hora del diálogo con la antropología filosófica, la moral, el derecho y otras disciplinas cabe preguntarse si su formulación un tanto abrupta no corre el peligro de reservar para la sola teología un concepto y una realidad como la de persona, de inmenso valor para la comprensión del hombre y también para el diálogo y la mediación entre fe y razón, teología y disciplinas sobre el ser humano. En este tema me parece que quizás nos encontremos ante un desafío. El origen y desarrollo teologal de la noción de persona está fuera de discusión. Pero pareciera necesario que su maduración filosófica (también en los dialógicos contemporáneos) quede preservada en diálogo con la teología, evitando que ésta, la teología, fagocite y absorba el término y la realidad mentada, corriendo el riesgo de una suerte de ghetto teológico y perdiendo al mismo tiempo una chance y una oportunidad valiosa de comunicación entre la teología y la antropología filosófica.

\section{b. CRISTOLOGÍA DE ARRIBA. MISIÓN Y PERSONA}

En el teodrama entre Dios y los hombres, el rol teatral se transforma en misión. En el caso del Hijo que entra en la trama del mundo, en el tiempo y en el entretejido de las libertades finitas encarnándose en Jesús, la misión es missio trinitaria, prolongación temporal de la eterna processio intratrinitaria.

Jesús vive una existencia en recepción (y en devolución eucarística, en acción de gracias) de cara al Padre en el Espíritu y, en forma arquetípica, recordando un texto célebre de nuestro autor, escrito muchos años antes de la Teodramática:

"El Hijo no puede hacer nada por sí solo (Jn.5,19-30; 12,49); no puede hablar por sí $(7,17)$. Por eso no hace su voluntad $(5,30)$, aunque tiene una voluntad propia $(5,6)$ y por eso no puede de ningún modo ser descrito como el ámbito vacío en que se sustancia Dios. Él es un sujeto, que hace multitud de declaraciones sobre sí mismo, y a quien le es propia una conciencia de su yo y de su personalidad hasta el inaudito "yo soy" puesto sin predicado $(8,24)$, pero es lo que es sobre esa base permanente de ¡no mi voluntad!, ¡no mi gloria! $(7,18)$. Su esencia, en cuanto Hijo del Padre, consiste en recibir de otro, del Padre, vida $(5,26)$, inteligencia $(3,11)$, espíritu $(3,35)$, palabra $(3,34)$, voluntad $(5,30)$, acción $(5,19)$, doctrina $(7,16)$, obra $(14,10)$, gloria $(8,54)$. 
Y recibirlo precisamente de tal modo que lo posee en sí $(5,26)$, y dispone de todo lo recibido como de cosa propia (Jn.10,18.28), pero no en una superación del recibir, sino como su confirmación perdurable, eterna, que le funda a él mismo. Si su haber dejara de ser por un momento un recibir y fuera un disponer autónomo desde la raíz, con eso mismo habría cesado a la vez de ser Hijo del Padre, habría dejado de ser fidedigno y debería requerir a los hombres en ese caso para que no le creyeran más (Jn.10,37).

La forma de existencia del Hijo, que le hace Hijo desde la eternidad (17,5), es ese ininterrumpido recibir del Padre todo lo que es él y él mismo. Y precisamente este recibirse a sí mismo le concede su Yo, su espacio interior propio, su espontaneidad, esa filialidad con que puede responder al Padre en devolución...

Pero si según Tomás su misión en el mundo es el aspecto que toma en las formas del mundo el hecho de que Él es engendrado (generatio), entonces su manera de existir en la tierra no será más que su aspecto en el ámbito de lo creado, la creaturización de esa forma celeste de existencia; existencia como recepción, como apertura a la voluntad del Padre, como ejecución subsistente de esa voluntad en ejecución ininterrumpida.

Igual que el Hijo en el cielo no empieza por ser una persona para sí, que acepte con posterioridad ponerse al servicio del Padre, así el Hijo en la tierra no empieza por ser un hombre para sí, que con posterioridad se abra hacia el Padre, para obedecer y hacer su voluntad, sino que el hecho de ser el abierto, el receptor, el obediente y cumplidor es lo que le hace hombre; ciertamente un hombre, pero sólo en cuanto lo hace este hombre.

Así como en el cielo el Hijo nunca entiende y aplica su modo de ser persona como algo excluyente, sino sólo como el lugar del recibir y de la respuesta, igualmente su autoconciencia no se le hace objetiva a él, hecho hombre (la tiene sólo para regalarla al Padre y a los hombres); para el hombre Jesús, su unión hipostática con el Logos no es ningún contenido religioso que, como tal, se haga temático, sino que más bien la forma de su autoconciencia humana es la expresión, en forma mundana, de su eterna conciencia de Hijo. Esto lo confirman las declaraciones de Jesús sobre sí mismo: están todas al servicio de su misión". TH 38-40.

La cristología de Balthasar es una cristología de la misión trinitaria del Hijo encarnado, esa misión es la forma económica de la processio, como hemos visto. Y su ciencia y conciencia se encuentran para Balthasar totalmente encuadradas en su misión soteriológica. Misión y persona se identifican en Jesús: su yo es idéntico con su misión, de modo que ésta no le es impuesta desde fuera, como una suerte de ley externa. La misión articula ambas realidades: la relación hacia el Padre enviante (en el Espíritu), presente y distinto del enviado, y la mirada hacia la ejecución de la misión, a ser ejecutada con las fuerzas humanas del enviado TDII/2.

La mirada teodramática es desde el comienzo "de arriba", descendente. La inspiración calderoniana ya es de algún modo "desde arriba", y la impostación de toda la obra teodramática de Balthasar originariamente es desde arriba. Nuestro autor, hijo de arquitecto y quizás también deudor de ese arte que trabaja el espacio, juega a menudo con analogías, imágenes y figuras espaciales aplicadas aquí analógicamente al teatro visto como teatro del mundo. 
Por ello, la mirada sobre Jesús desde la missio-rol trinitaria tiene ya desde siempre un componente descendente y kenótico. Sabemos que el autor también habla de kénosis en las relaciones trinitarias ad intra, tema quizás excesivamente focalizado en la recepción de su obra. En efecto, en una carta personal a Thomas Krenski, el autor relativiza sus afirmaciones: "Auf dem Kénosen in der Trinität nicht zu sehr herumreiten. Das analogatum princeps ist Phil.2 und Kol.1,17! Die innergöttlichen kenosen gehören zwischen Gänsefüschen". Sobre las kénosis en la Trinidad no darle más vueltas. El analogatum princeps es Fil. 2 y Col 1,17. Las kénosis intratrinitarias hay que ponerlas entre comillas! (carta del 19.2.87). El mismo autor, entonces, matiza o redimensiona sus afirmaciones invitando a sus lectores a evitar una suerte de vértigo kenótico que abra sospechas de un enredo de la Trinidad inmanente con la Trinidad económica, riesgo que el autor desea expresamente evitar, especialmente en sus discusiones con Moltmann. Su acento en la missio trinitaria del Hijo, sin embargo, nos hace pensar en una teología quizás preponderantemente joánica y de algún modo alejandrina. Inspirado en Schell, y no lejos de afimaciones de Kasper, Balthasar subraya la mencionada identidad entre persona y missio trinitaria, lo que explica su perfecta entrega obediente a la misión encomendada por el Padre. No es extraño que en este contexto se diera un diálogo polémico con Rahner, partidario de una cristología de abajo, pensada en un marco evolutivo (con dos Aktzentrum en Jesús) y ciertamente más cercana a la teología antioquena y no sin influencias de Máximo el Confesor.

\section{RIESGO DE NEOCALCEDONISMO}

Rahner va a criticar la cristología balthasariana como neocalcedoniana, en el sentido de una perspectiva descendente, no propiamente monofisita pero sí insuficientemente atenta a la plenitud de la naturaleza humana tal como la describe Calcedonia, en una suerte de retroceso a la previa teología ciriliana de Éfeso, que de algún modo dominaría el Jesús de Balthasar. La mirada unidimensionalmente joánica balthasariana daría pie a la crítica del teólogo de Innsbruck.

Como lo hemos visto hasta ahora, es indudable el carácter descendente de la cristología de nuestro autor. Es difícil que una perspectiva cristológica tan raigalmente trinitaria y tan fundada en la missio no tenga un sello descendente definitivo y determinante. Pero cabría preguntarse también si la imagen completa de Jesús que transmite nuestro autor, no tiene elementos suficientes como para obligar a repensar y matizar aquella estimación negativa de neocalcedonismo. Así, por ejemplo, su teología de la conciencia unvordenklich, que desea dar cuenta del acompasamiento divino al ritmo humano en el desarrollo del hombre Jesús, nos muestra una percepción de la consistencia humana y su paulatino desarrollo como destino humano libre, bien diversa de las posiciones algo monofisitas de la teología neocalcedonense. En relación con ello, el autor se plantea la articulación de esta conciencia divina de Jesús con su mediación histórica y humana. De la misma manera nuestro autor admite un espacio real para una progresiva iluminación de la conciencia de su misión, no obstante su carácter de conciencia inmemorial y una iniciación siempre más profunda del significado y la amplitud de su misión (TD II/1, 164). 
El acento descendente de la cristología balthasariana se articula con una conciencia aguda del status exinanitionis de Jesús. Y aun su discutida teología de la "inversión trinitaria" pretende mostrar a un Jesús obediente que vive y cumple paso a paso su missio sin anticipar nada en el desarrollo de su propio destino, en relación con el juego de las libertades, frente al Padre y frente a los hombres. Aquí se plantea el tema de la ignorancia de la "hora" en su fase decisiva, y de no conocerla no sólo cronológica sino esencialmente (Mt.24,36), dejándola en las manos del Padre y en la guía del Espíritu (TD II/2, 148). En Das Ganze im Fragment hay una teología del tiempo, de la paciencia y de las edades de Jesús, temas muy queridos por el autor, que nos muestran su mirada sobre la consistencia real del hombre Jesús. Por ello el autor reconoce espacio para la fe en Jesús, por lo menos en un sentido análogo en tanto "guía y consumador de nuestra fe" (Heb.12,2) (TDII/2, 157). Balthasar subraya también por ello el mérito de la entera existencia redentora de Jesús, como vemos en el texto siguiente, de su Teología de la Historia:

"El concepto que Él tiene de su hora -y tiene, en efecto, tal saber- encuentra una medida en lo que el Padre le revela de ella. Por tanto (puesto que la hora es el resumen de toda su misión) se puede decir más generalmente: su saber de Dios hombre encuentra su medida en su misión. No es él mismo medida, sin más, sino lo medido, mientras que la misión es la medida y es lo que mide. Su perfección es su obediencia, que no se anticipa. A esa regla tiene que amoldarse el uso de sus facultades. Si se imaginara el saber de Cristo como si él dispusiera sus actos concretos en el tiempo igual que un ajedrecista genial, que desde la tercera jugada ve toda la partida y dispone las piezas para una partida que en el fondo ya está para él resuelta, entonces se suprimiría la entera temporalidad de Jesús, pero también su obediencia, su paciencia, el mérito de su existencia redentora, y ya no sería prototipo de la existencia cristiana, ni, por tanto, de la fe cristiana. Ya no estaría autorizado para contar las parábolas del aguardar y esperar con que describe la vida en su seguimiento". TH 47.

Aquí es donde planteamos entonces lo que podríamos llamar un balance entre "cristología de arriba" y "cristología de abajo" en nuestro autor, donde ambas perspectivas se abren la una a la otra hasta completarse la una con la otra. No obstante entonces lo determinante de su cristología de la missio descendente, su aguda distinción entre el status exinanitionis y el status exaltationis de Jesús, abre su cristología a una consideración de la humanidad de Jesús lo suficientemente importante y consistente como para lograr un cierto equilibrio y apertura mutuos de los que hablábamos. Lo que no obsta a reconocer una cierta tensión inevitable en su imagen de Jesucristo.

\section{LA CRUZ}

Hay que recordar, ante todo, que el autor pone un acento singular en el amor de Dios Padre que entrega al Hijo para obrar la reconciliación del hombre consigo (TD III 223) y el amor de Hijo que en el Espíritu obedece al Padre. Esto lo advertimos en los dos temas teológico bíblicos subrayados por Balthasar, tanto el tema de la entrega del Hijo como el tema del amor que sostiene la obra salvífica. 
En relación con lo anterior, a nuestro autor se le ha criticado su concentración unidimensional en la Cruz y el abandono (y el consiguiente descenso a los infiernos), con desmedro de la consideración de toda la vida redentora de Jesús, de su anuncio del Reino y de sus acciones salvíficas. Este acento es indudable, y es aún subrayado a veces por el mismo Balthasar, por ejemplo, en su lectura de la llegada de la hora joánica en la vida de Jesús.

Como lo terminamos de decir, su teología de las edades de Jesús en Das Ganze im Fragment, su teología de la paciencia y obediencia (y no anticipación de la hora) vividas paso a paso, según el Espíritu lo iba orientando, su mirada sobre los signos, su teología de la misión en su conjunto en la Teodramática (no sólo en relación con la muerte, aunque sí incluyéndola), todas ellas pueden brindar elementos para recuperar una teología del entero "status exinanitionis" del Hijo encarnado en su conjunto.

Nuestro autor describe la Stellvertretung redentora, en diálogo con Rahner, su interlocutor invisible:

"Hay que decir también positivamente: hacerse solidario de los perdidos es más que morir por ellos representándolos de una manera exterior; es también más que proclamar la palabra de Dios de una manera tal que esta proclamación conduzca accidentalmente, por la oposición que suscita entre los pecadores, a una muerte violenta; es más también que asumir solamente su destino común e inevitable de muerte; es más, en fin, que tomar simplemente sobre sí de modo consciente la muerte constitutivamente inmanente, desde Adán, a toda vida de pecador, y hacer personalmente de esta muerte un acto de obediencia y de don de sí a Dios... Más allá de todo esto -que puede tener su valor relativo- el acto redentor consiste en asumir, de una manera absolutamente única, el pecado del mundo, y es el acto del Hijo absolutamente único del Padre, cuya doble naturaleza, humana y divina (que es más que un caso supremo de antropología trascendental), es sólo capaz de una misión semejante”. MP 133-134.

Respecto a esta Stellvertretung (estudiada acabadamente por Menke desde un lado católico y Bieler desde un lado evangélico), diríamos que es una idea absolutamente central de nuestro autor, quien es quizás el exponente de más relieve en tierra católica -junto a Kasper y Ratzinger, a la espera del tomo segundo de su Jesús-, de esta realidad de la Stellvertretung o representación inclusiva. La pro existencia culmina en la Stellvertretung de la Cruz, del abandono y del Descenso, hasta recrear de raíz al hombre viejo a partir de su Stellvertretung como Resucitado, Señor ahora del Espíritu que derrama en su Iglesia.

\section{E. EL DESCENSO A LOS INFIERNOS}

Son conocidas las críticas a nuestro autor, sobre todo en su exposición de MP y en algún pasaje de TD III. El centro de lo objetado es aquello de la experiencia del mal como tal o la visio peccati, donde pareciera que Jesús tuviera una experiencia infernal de condenado (más allá del Scheol, infierno como lugar propio de condenados), al mejor estilo del calvinismo o zwinglismo más puro y duro. Los matices aportados 
en la TD III (Boulgakov, Feuillet) como "una experiencia sin analogía" no bastarían para modificar la crítica.

A ello habría que agregar que a esta mirada sobre la Stellvertretung, hasta en la experiencia de la condena, se agregaría la concepción balthasariana (inspirada en Teresita y en Péguy y recibida en el Catecismo) de la "esperanza universal de salvación". Interpretada ésta por sus críticos como una suerte de apocatástasis encubierta, que calzaría justamente con la experiencia infernal: en tanto que Cristo experimenta el infierno, vacía el infierno de todo condenado.

Sin desmedro de volver más adelante sobre el tema de Adrienne von Speyr, parece claro que nuestro autor ha querido traducir teológicamente experiencias místicas de quien ha sido su discípula. Las citas del Cusano no bastan para mostrar en la tradición una huella importante, en el sentido que le da el autor. Hay aquí una innovación que no parece lejana, efectivamente, a la tradición calvinista y zwingliana, aunque venga encuadrada en un contexto diverso como es el de la Teodramática (interesante, en este sentido, las discusiones entre Menke y Bieler sobre la Stellvertretung). Por ello nosotros no acompañamos al autor en estas afirmaciones algo extremas sobre el Descenso (experiencia del mal como tal, visio peccati), que nos parecen carentes de fundamento último en la Palabra de Dios y en la Tradición.

Pero aquí no termina el balance sobre este tema delicado. En efecto, la vuelta al tema del Descenso en general como Hades o Scheol en la teología del siglo XX (Cf. el excelente capítulo de Gesché en su libro sobre Cristo, Ratzinger ya en la Introducción al Cristianismo, González de Cardenal en Fundamentos de Cristología II y aún la plegaria eucarística cuarta) significa una revalorización de un aspecto de la Cruz que había quedado algo oscurecido u olvidado.

Y su interpretación del Descenso como una realidad eminentemente pasiva, y no activa ni triunfal, ha sido bien puesto de relieve por nuestro autor, dando pie de este modo a considerar la iconografía oriental como una retroproyección pascual, que expresa la salida de Jesús de los infiernos, ya resucitado de entre los muertos, acompañado de Adán y los demás, subrayando su contenido soteriológico.

Con otras palabras el descenso es una dimensión de la muerte y, en este sentido, un aspecto de la muerte (y de la Cruz). Jesús no sólo pasó por la muerte: Jesús estuvo muerto entre los muertos durante un lapso de tiempo (por lo menos análogo), horizontal (Claudel), yaciente, compartiendo el Scheol de Adán, de los hombres anteriores a su venida (Heb.11,40).

Como dice González de Cardedal, "la misma muerte como pasividad absoluta" (Fundamentos II, 546). Todo ello no obsta a una teología del anuncio y el ofrecimiento de la salvación a los hombres que no han conocido a Cristo (con su matiz de universalidad de la redención), con su propia miga teodramática y en el sentido de la

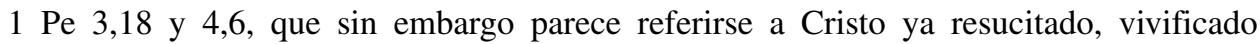
en el Espíritu (Schnackenburg).

Recientemente, de la lectura de las recensiones de la tesis de Alyssa Lyra Pistick (Light in darkness, H.U. von Balthasar and the Catholic Doctrine of Christ's Descent into Hell, Eerdmans, G. Rapids, 2007), me queda la impresión de una defensa de la consideración del descenso como descenso activo y triunfal, lo cual me parece una vuelta a una concepción discutible que no percibe los aportes positivos y válidos de la teología, la exégesis y la filosofía recientes (pienso, por ejemplo, en Gesché, buen lector de 
Ricoeur y atento a la filosofía del lenguaje), respecto a este aspecto importante de la teología de la Cruz. Posición triunfalista del Descenso que permanece excesivamente tributaria de las preocupaciones antropológicas (respetables, por cierto) del Medioevo sobre la unidad de hombre y Dios en Cristo. Tampoco resulta convincente la afirmación lapidaria y segura de que el descenso triunfal de Cristo a los infiernos sea vinculante para la fe. Tanto desde el punto de vista de la Palabra de Dios como de la Tradición, no veo afirmaciones definitivas respecto a nuestro tema que nos lleven a considerarlo obligante.

Esta revalorización de la teología del Descenso, con su proyección soteriológica, se la debemos también a Balthasar, y constituye una contribución importante a la teología cristiana de la Cruz y la Resurrección, del Misterio Pascual en su integridad. Y esto dicho sin desmedro de lo que hemos dicho sobre sus afirmaciones sobre la visio peccati por parte de Jesús.

Vinculado con nuestro tema, una consideración aparte requeriría su valiosa teología de la Resurrección, en su obra sobre el Misterio Pascual, de tintes joánicos, escrita en diálogo con Koch, Grass, Künneth y Pannenberg, que merecería una valoración especial por su amplitud, su carácter polifacético y ponderado (por ejemplo, respecto al carácter histórico y metahistórico de la Resurrección), de alguna manera anticipatorios de discusiones y desarrollos posteriores (Cf.G. Essen).

La inserción del hombre y la Iglesia en la obra de Cristo son vistas también a menudo desde la figura de María como ícono de la Iglesia que se asocia a la obra de Cristo. María participa de manera propia en la representación de Cristo como madre y esposa-Iglesia. Balthasar ve ya el sí de la Anunciación en forma primero maternal y luego nupcial representativa de toda la Iglesia. Con su sí María es la servidora disponible totalmente a su misión única en el plan de salvación. Como Madre y Esposa asiente a las nupcias del Verbo con la humanidad, a quien María representa.

Pero su sí concentrado en un momento peculiar de cara al ángel luego abarca toda su vida y se encuentra presente de un modo especial en el momento de la Cruz. Allí María consiente (junto a Juan) a la oblación de Jesús con un acto de extrema disponibilidad, participando personal y representativamente en su entrega al Padre. Y aquí también María con su misión representa como nueva Eva a la Iglesia Esposa en su asociación a la ofrenda de Jesús, nuevo Adán. Su participación femenina es simultáneamente pasiva y activa, y abre el arco de la misión personal de todos en la Iglesia. En efecto, Cristo nos abre nuestro lugar filial con su acción redentora, pero cada uno está llamado a vivir su propia misión eclesial articulada en la misión suya.

\section{f. SUPERACIÓN DE LA NEOESCOLÁSTICA}

La apertura estético-dramática abre con una frescura nueva el contacto con la revelación y en particular el contacto con la figura de Jesucristo. Y esta apertura descansa, como lo hemos dicho, en un personalismo dialógico fundado metafísicamente. La fascinación provocada por la figura nos recuerda pasajes de Guardini o de James Dunn, donde la impresión o el impacto provocados por la figura constituyen el hecho fundante de toda la revelación. El camino de la razón estética que percibe la gloria que emana de la figura concreta de Jesucristo llevará luego al centro del tríptico, la Teodramática y luego a la Teológica. 
La Teodramática rebalsa los marcos de la teología postridentina (en su postura apologética, en su modo de inspiración en la Escritura, en su diálogo con la filosofía, en su diálogo con la literatura). Desde su impostación literario filosófica, desde dentro de la Trilogía, supera trascendiendo la teología de escuela neoescolástica (Schleifung der Bastionen), sin desmedro de un excelente conocimiento de la Tradición y de santo Tomás, por parte de nuestro autor, buen discípulo de Henri de Lubac, como bien lo subraya Nikolaus Lobkowicz en distintas contribuciones. Dialoga con la modernidad, desde su preferencia por la figura objetiva y su herencia de Goethe, lo cual supone una distancia crítica con respecto a una filosofía trascendental, y escribe su teología contemplando largamente la Palabra. Esta expresa distancia de la filosofía trascendental no deja de alejarlo de muchos exponentes de la teología contemporánea.

Teólogo y literato, en una imbricación mutua inescindible, además de filósofo, con un profundo sentido del misterio, con una sensibilidad peculiar para penetrar la palabra y el texto, ayudado por una memoria prodigiosa, tiene un lugar singular, algo out sider diríamos, en la teología contemporánea. Algún autor llega a caracterizarlo por esto como un teólogo postcrítico y postmoderno. El cardenal Ouellet afirma, en este sentido: "Creo que las secuelas del racionalismo en la teología moderna no serán extirpadas sino cuando el mensaje de la percepción del ser como amor haya sido recibido conjuntamente por la filosofía y la teología" (Mensaje de la teología de Balthasar a la teología moderna, en Vermittlung als Autrag, 123, Johannes, 1995).

Por ello, el tono de olímpica seguridad de Manfred Hauke en su recensión de la tesis de Lyra Pistick (F.K.Th.08,1,p.40), que mencionábamos recién, me parece un buen ejemplo de lo que podríamos llamar una escolástica racionalista, que se expresa sobre realidades infinitamente complejas con una certidumbre envidiable. Hablando del tema del Descenso, Adolphe Gesché, utiliza prudentemente y con razón la expresión "salvo meliore iudicio", advirtiendo en forma consciente las dificultades exegéticas y teológicas del tema, y atento a que la teología muchas veces balbucea su objeto con conciencia del misterio. Para no hablar del mismo autor, Balthasar, quien llegaba a afirmar en una conversación personal, respecto a la resurrección en la muerte: "nous ne savons rien".

\section{g. EL BALANCE DEL APORTE DE ADRIENNE}

Este me parece un tema casi imposible. Porque la obra de un autor es fruto también de su circunstancia. Y Adrienne pertenece a la vida de Balthasar de un modo peculiarísimo. Discutir su mutua influencia me parece inútil: facta non disputatur. Ello no obsta a que ciertas formulaciones muy audaces que parecen de su proveniencia - de Adrienne en Balthasar- pidan a veces un intento de mayor claridad teológica (-por ejemplo, justamente la teología del descenso a los infiernos que venimos de mencionar).

Pero pienso que a la hora de su estudio y valoración, conviene que la inmensa obra balthasariana, suficientemente compleja, sea estudiada desde él mismo, malgré lo que el autor pide en Unser Auftrag. Tal como llega a nuestras manos y en sí misma, y con todas las influencias recibidas, en tanto su teología es en sí misma sinfónica: Adrienne, Allers, Guardini, Przywara, Lubac, Barth, Siewerth, Ulrich, etc. De la misma manera que la inmensa y notable obra de Adrienne ha de ser estudiada también desde ella misma, más allá de las influencias recibidas. 


\section{CONCLUSIÓN}

Concluyamos nuestra conversación sintetizando entonces sus puntos principales:

En primer lugar el planteo teodramático visto desde una libertad creadora que llama a existir a una libertad creada que ha de realizarse en diálogo con aquélla, para lo cual hará falta una cierta latencia de la presencia divina (zimzum) que deje espacio para que la libertad creada pueda crecer y desarrollarse. Latencia que no obsta al acompañamiento divino del hombre.

En segundo lugar, Dios, fiel a su creación y a su alianza con el hombre (libertad creada) que corre el riesgo de perderse, envía a su Hijo en su missio redentora. La obediencia proexistente de Jesús a su Abbá es vista desde una verdadera identidad entre persona filial y misión filial trinitaria (misión como prolongación de la processio).

En tercer lugar, Jesús vive una entera y lenta vida humana en recepción y al servicio proexistente de los otros, en el anuncio del reino de su Padre. El Espíritu va apuntándole momento a momento el camino de su Padre. Su existencia en recepción, su pro existencia no son sino la traducción o la creaturización de su ser relatio subsistens (intratrinitaria) hacia el Padre y hacia el Espíritu Santo.

En cuarto lugar el rechazo y el choque contra Jesús y su mensaje del Reino culminan en la Cruz y en el abandono, donde Jesús entrega su vida representándonos inclusivamente en nuestro lugar de pecadores. El autor considera esta representación o Stellvertretung como radicalmente abierta a ser participada.

En quinto lugar, vimos cómo Balthasar expone una teología del descenso a los infiernos, como consecuencia y culminación del misterio de la Cruz. Expusimos allí nuestro reparo a ciertas afirmaciones extremas del autor.

En sexto lugar nos parecía advertir en Balthasar un acento estético dramático novedoso, que supone en los hechos una superación de la neoescolástica. Subrayamos el sello personalista dialogal de su pensamiento, al mismo tiempo que su fundamento metafísico, apoyado en la analogía entis, los trascendentales y una metafísica del amor trinitario.

En séptimo lugar, nos parecía que la interpretación y el estudio del autor debían ser hechos a partir de él mismo.

En octavo lugar, es bueno admirar la fecundidad del pensamiento de Balthasar, que ha abierto un abanico enorme de reflexión al que aludiremos sin ninguna pretensión de ser exhaustivos y citando algunos autores sólo a título de ejemplo.

Reflexión filosófica, a partir de la idea fundamental del ser como amor, pensado desde la relatio mutua trinitaria, desarrollada de un modo peculiar tanto por quienes vienen de la fenomenología, como Marion o Hemmerle con su ensayo sobre teología trinitaria, como quienes se inspiran en Ulrich y sus discípulos, como Stephan Oster en su antropología del don o Schulz con su Sein und Trinität.

Reflexión de teología fundamental, desde Fisichella y Oakes, pasando por Schulz y Lochbrunner, y Holzer en su agudo trabajo sobre Rahner y Balthasar.

Reflexión trinitaria, como la de Norbert Hoffmann, meditando sobre la expiación desde el misterio trinitario o Gisbert Greshake, con su tratado de dogmática trinitaria. 
Reflexión cristológica, con los ya mencionados Menke y Bieler, Marchesi, Krenski, pero también, desde una distancia crítica dialogante, las sucesivas cristologías de don Olegario González de Cardenal (desde la primera, a Los Cuatro Poetas, a la Entraña, a la segunda Cristología y a los dos Fundamentos de Cristología). También las sucesivas contribuciones de Schwager-Girard no dejan de tener un sello teodramático explícito. Es interesante, en este sentido, ver la común afinidad literaria de Girard y Baltasar.

Reflexión antropológico teológica, como la llevada a cabo por Schindler padre en su aguda crítica a la cultura norteamericana contemporánea, o el trabajo de Stinglhammer, o el lúcido trabajo de Ángel Cordovilla Pérez, sobre las antropologías de Rahner y Baltasar.

Reflexión eucarístico eclesial, como el estudio de Bätzing. Servais.

Reflexión espiritual (mariana e ignaciana), como los estudios de Ouellet y

Reflexión escatológica y de teología de la historia, como el bello trabajo de Wallner o el libro de Mario Imperatori.

Y tantos otros trabajos que han influido e influyen no sólo la reflexión y el pensamiento, sino la espiritualidad y la vida concreta vividas en la Iglesia contemporánea. Y esto no sólo en la vida de la Iglesia ad intra, sino también en su diálogo con el mundo, con las iglesias y con las otras religiones.

\section{RESUMEN}

Habría que preguntarse si la imagen completa de Jesús que transmite nuestro autor no tiene elementos suficientes como para obligar a repensar y matizar aquella estimación negativa. Así, por ejemplo, su teología de la conciencia unvordenklich, que desea dar cuenta del acompasamiento divino al ritmo humano en el desarrollo del hombre Jesús, nos muestra una percepción de la consistencia humana y su paulatino desarrollo como destino humano libre, bien diversa de las posibles derivaciones algo monofisitas de la teología neocalcedonense.

El acento descendente de la cristología balthasariana se articula con una conciencia aguda del status exinanitionis de Jesús. Y aún su discutida teología de la "inversión trinitaria" pretende mostrar a un Jesús obediente que vive y cumple paso a paso su missio sin anticipar nada en el desarrollo de su propio destino, en relación con el juego de las libertades del hombre Dios frente al Padre y frente a los hombres. En Das Ganze im Fragment hay una teología del tiempo, de la paciencia y de las edades de Jesús, temas muy queridos por el autor, que nos muestran su mirada sobre la consistencia real del hombre Jesús. Balthasar subraya también por ello el mérito de la entera existencia redentora de Jesús.

Palabras clave: Balthasar, Cristología, Personalismo, Drama, Libertad.

\section{ABSTRACT}

One would have to wonder whether the complete image of Jesus that our author transmits wouldn't already have sufficient elements for forcing us to rethink and nuance that negative estimation. For example, his theology of conscience, or unvordenklich, with which he desires to account for the divine measuring of the human rhythm in the development of 
the man Jesus, shows us a perception of human consistency and its steady development as free human destiny, rather different from the possible, somewhat monophysite derivations of neo-Chalcedonian theology.

The descendent accent of Balthasarian Christology is articulated with a sharp consciousness of the status exinanitionis of Jesus. Even his controversial theology of "trinitarian inversion" attempts to show us an obedient Jesus who lives and fulfills his mission step by step without anticipating anything in the development of his own destiny, in relation to the set of freedoms of the man-God with regard to the Father and to his fellow men. In Das Ganze im Fragment there is a theology of time, of patience and of the distinct ages of Jesus, themes close to the author's heart, that show us his perspective on the real consistency of the man Jesus. Balthasar underlines in this way, as well, the merit of Jesus' entire redeeming existence.

Key words: Balthasar, Christology, Personalism, Drama, Freedom. 